\title{
Status and Perspective of China's Nuclear Safety Philosophy and Requirements in the Post-Fukushima Era
}

\author{
Zhiyi Yang ${ }^{1}$, Fengchen $L i^{2}$ and Guohan Chai ${ }^{1 *}$ \\ ${ }^{1}$ Nuclear and Radiation Safety Center, MEE, Beijing, China, ${ }^{2}$ Key Laboratory of Efficient Utilization of Low and Medium Grade \\ Energy (Tianjin University), MOE, School of Mechanical Engineering, Tianjin University, Tianjin, China
}

OPEN ACCESS

Edited by:

Yapei Zhang,

Xi'an Jiaotong University, China

Reviewed by:

Penghui Chai,

Japan Atomic Energy Agency, Japan

Shanshan Bu,

Chongqing University of Technology,

China

Yidan Yuan,

China Nuclear Power Engineering Co.

Ltd., China

*Correspondence:

Guohan Chai

chaiguohan@chinansc.cn

Specialty section:

This article was submitted to

Nuclear Energy,

a section of the journal

Frontiers in Energy Research

Received: 22 November 2021 Accepted: 07 December 2021

Published: 03 January 2022

Citation:

Yang Z, Li F and Chai G (2022) Status and Perspective of China's Nuclear Safety Philosophy and Requirements in the Post-Fukushima Era.

Front. Energy Res. 9:819634.

doi: 10.3389/fenrg.2021.819634
The significant impact brought by a severe nuclear accident at the Fukushima Daiichi Nuclear Power Plant (NPP) in Japan in March 2011 has made global regulators to review the requirements against severe accidents. In China, comprehensive safety inspection and external hazard safety margin assessment on NPPs were carried out, regulatory requirements on improvement measures for NPPs based on the inspection were given, the nuclear safety 5-year plan was made and executed, and the safety requirements on the new NPP design were drafted. The Nuclear Safety Law came into effect in 2018. The "Code on the Safety of Nuclear Power Plant Design" (HAF102) was revised in 2016, and relevant safety guides were developed. In this article, improvement actions and requirements about NPP safety in China over the past 10 years were reviewed, and the nuclear safety philosophy and requirements including practical elimination, classification of accident conditions, and defense in depth portable equipment were elaborated. In summary, some suggestions of NPP safety in China in the future were provided.

\footnotetext{
Keywords: Fukushima nuclear accident, nuclear safety, practical elimination, defense in depth, severe accident, portable equipment
}

\section{INTRODUCTION}

As of October 2021, there were 51 Nuclear Power Plant (NPP) units in operation and 14 units under construction in China (IAEA, 2021). In order to improve the industrial structure and energy mix and promote toward the goals of achieving peak carbon emissions and carbon neutrality, the Chinese government would take active and well-ordered steps to develop nuclear power under the premise of ensuring its safe use (State Council of China, 2021). China has been adhering to a rational, coordinated, and balanced nuclear safety strategy and taking nuclear safety as an important element of China's overall national security framework. Under the effective regulation of nuclear safety, China had maintained a good nuclear safety record for a long time, and the performance indicators of NPPs are generally good. There were no incidents or accidents at or above Level 2 under the International Nuclear and Radiological Event Scale (INES). China has established a nuclear safety regulatory system and regulatory standards in line with international specifications. In 2000, 2004, 2010, and 2016, the International Atomic Energy Agency (IAEA) conducted four comprehensive reviews of China's nuclear and radiation safety regulation, giving fully positive recognition to China's good practices and experiences (State Council Information Office of China, 2019). 
TABLE 1 | Percentage changes in positive opinion toward nuclear power pre- and post-Fukushima (Hayashi and Hughes (2013)).

\begin{tabular}{|c|c|c|c|}
\hline Country & & Pre-Fukushima & Post-Fukushima \\
\hline \multirow[t]{9}{*}{ OECD countries } & Canada & 51 & 43 \\
\hline & The United States & 53 & 47 \\
\hline & Austria & 13 & 9 \\
\hline & France & 66 & 58 \\
\hline & Germany & 34 & 26 \\
\hline & Italy & 28 & 24 \\
\hline & Switzerland & 40 & 34 \\
\hline & Japan & 62 & 39 \\
\hline & South Korea & 65 & 64 \\
\hline \multirow[t]{3}{*}{ Non-OECD countries } & China & 83 & 70 \\
\hline & India & 58 & 49 \\
\hline & Russia & 63 & 52 \\
\hline Global average & 57 & 49 & \\
\hline
\end{tabular}

On 11 March 2011, the Great East Japan Earthquake at magnitude 9 happened off the Pacific coast of Japan and resulted in $14-$ to $15-\mathrm{m}$-high tsunami waves which overwhelmed the tsunami barriers of the Fukushima Daiichi NPP site. Systems and equipment of the primary and backup powers as well as the ultimate heat sink of all six units on the site were flooded. Loss of the off-site power occurred due to the earthquake before the tsunami. Units 1-5 of the Fukushima Daiichi NPP experienced extended station blackout (SBO) events, and severe accident occurred in Units 1,2 , and 3 . The radioactive material escaped from the reactors and further released directly to the environment either in a controlled manner or in an uncontrolled manner due to hydrogen explosion. The Fukushima Daiichi Nuclear Accident (FDNA) caused serious consequence and brought deep effect to the nuclear industry (IAEA, 2015).

However, with more than 440 NPP units in operation around the world, it seems unlikely to give up nuclear energy completely (Table 1), which is an inevitable option for some countries to secure energy supplies, optimize their energy mix, and contribute to reducing carbon emissions (Hayashi and Hughes, 2013). Reexamination and reflection on nuclear safety to ensure and improve the nuclear safety became an urgent issue in the peaceful use of nuclear energy once again. A series of actions, including safety inspections, re-evaluation, and update of nuclear safety requirement and standard, were implemented to improve the nuclear safety level among the main nuclear organizations such as IAEA and Western European Nuclear Regulators' Association (WENRA), and countries such as the United States and United Kingdom (US NRC, 2011; WENRA, 2013; UK ONR, 2014; IAEA, 2016a).

In this study, the post-Fukushima nuclear safety improvement actions in China were reviewed, the nuclear safety philosophy and requirements were introduced and elaborated, the future development of nuclear safety in China was discussed, and some suggestions were put forward. Several inspections, such as nuclear safety considerations, emergency preparedness and response, radiological consequence, and post-accident recovery (IAEA, 2015), are relevant to FDNA experience and lessons, and only part of nuclear safety considerations are referred to in this article. Note that the research on FDNA is still ongoing, and the technical positions may be changed along with lessons learned in the future.

\section{POST-FUKUSHIMA NUCLEAR SAFETY IMPROVEMENT ACTIONS IN CHINA}

A series of nuclear safety improvement actions were taken in China after the FDNA, mainly including:

1) Comprehensive Safety Inspections (CSIs) were carried out.

2) General Technical Requirements (GTRs) on post-Fukushima improvement actions (trial version) were published.

3) Safety margin evaluation for beyond design-basis external events was performed.

4) The Nuclear Safety Plan (NSP) was made and executed.

5) Safety requirements on new NPP designs were drafted, and "Code on the Safety of Nuclear Power Plant Design" (HAF102) was revised.

6) Relevant safety guides and technical documents of HAF102 were developed.

The FDNA also prompted the establishment of the Nuclear Safety Law, which had come into effect in 2018. This is the first law in the nuclear safety field in China which was launched to strengthen publicity on the rule of law and to improve the system, to reinforce the strict regulation by law, and to implement the nuclear safety responsibility.

\section{Comprehensive Safety Inspections}

The CSIs (NNSA NEA CEA, 2012) were conducted from March 2011 to December 2011 to find out potential safety weaknesses according to laws, rules, standards in force, and latest IAEA documents. Eleven aspects were focused on, including external events taken into account in siting based on recent developments, review and reassessment of the flood prevention design basis, and prevention and mitigation of severe accidents. The main general conclusions of the CSI are as follows:

1) The design, construction, and operation of NPPs satisfy requirements of Chinese safety regulations and reach the 


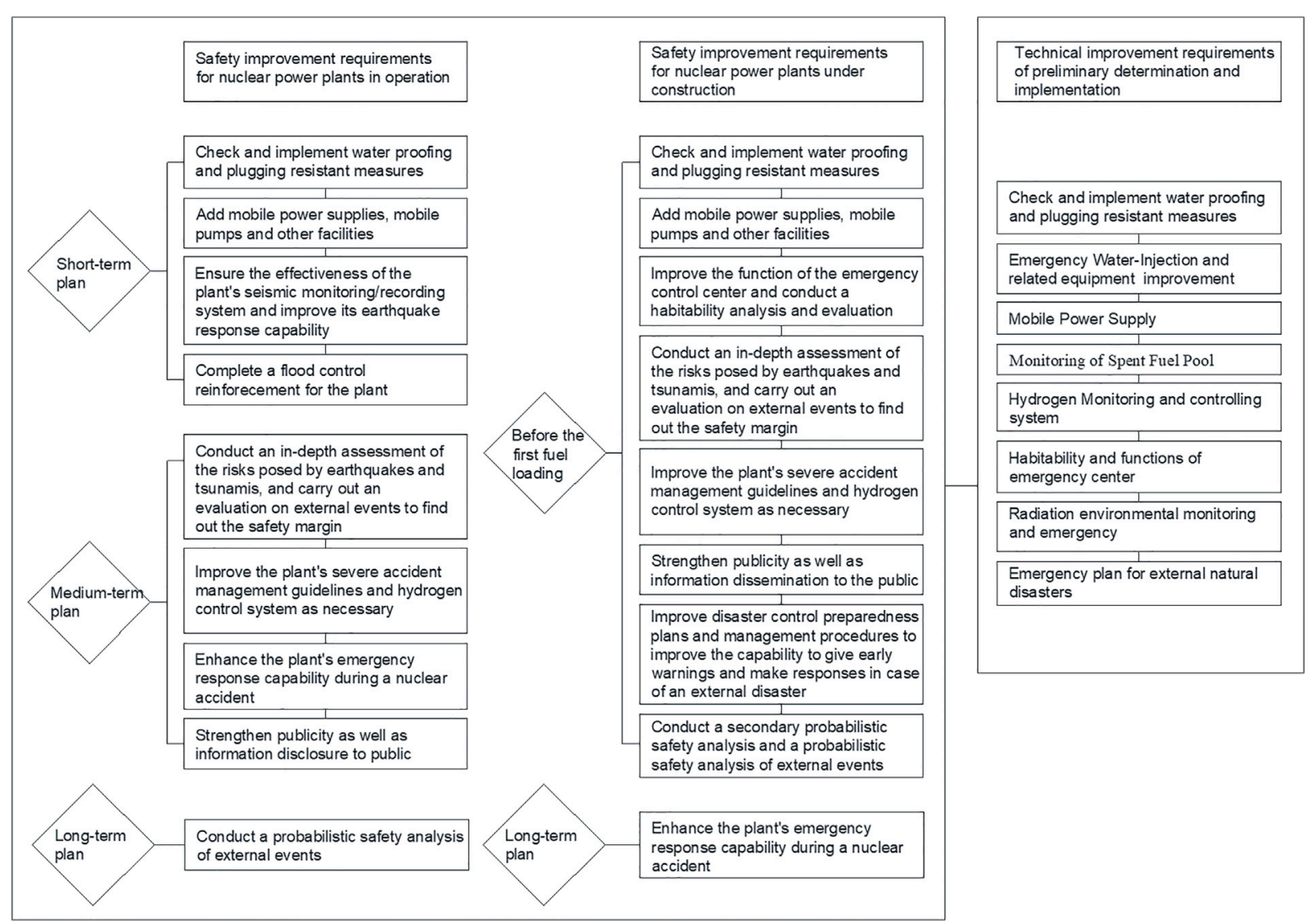

FIGURE 1 | Improvement actions and technical measures for China (2012).

safety level in IAEA new requirements. The NPPs have fully ability to prevent design-basis accident (DBA) and have basic ability to prevent and mitigate severe accidents, and risk is under control.

2) A number of specific issues have been identified. Qinshan NPP's flood prevention capacity is not fully adequate according to the latest regulation requirements, some NPPs have not established and conducted severe accident management guideline (SAMG), and effects of tsunami triggered by earthquake need further investigations and assessment.

In order to enhance the safety level of the NPPs further, some improvement actions were put forth, including short-, mediumand long-term improvements (Figure 1) (Zhang and Li, 2014).

\section{General Technical Requirements on Post-Fukushima Improvement Actions (Trial Version)}

In order to provide guidance for the NPPs to carry out postFukushima improvement measures, the common improvements were standardized, and technical integrity was reached during the implementation, the GTRs on post-Fukushima improvement actions (trial version) were compiled (NNSA, 2012a). It can also coordinate the depth and broadness of safety improvement strategies and set definite improvement acceptance criteria. Eight specific technical requirements are given, which can be seen in Figure 2.

The GTR specified some conditions and requirements in implementation of the improvements, such as the flood considered (design-basis flood plus superimpose once in 1,000 years' precipitation), portable equipment sets, capacity and preparation time ( $6 \mathrm{~h}$ after reactor trip), hydrogen amount considered, emergency center seismic class, and habitability criteria. The requirements were issued as a trial version because it took into account the preliminary experience feedback from the FDNA and would be amended and improved while more progress is made and more knowledge is acquired through domestic and international research and studies on the FDNA.

\section{Safety Margin Evaluation for Beyond Design-Basis External Events}

In February 2012, the National Nuclear Safety Administration (NNSA) requested operating NPPs to carry out comprehensive assessments of the plants' safety margin to beyond design-basis 


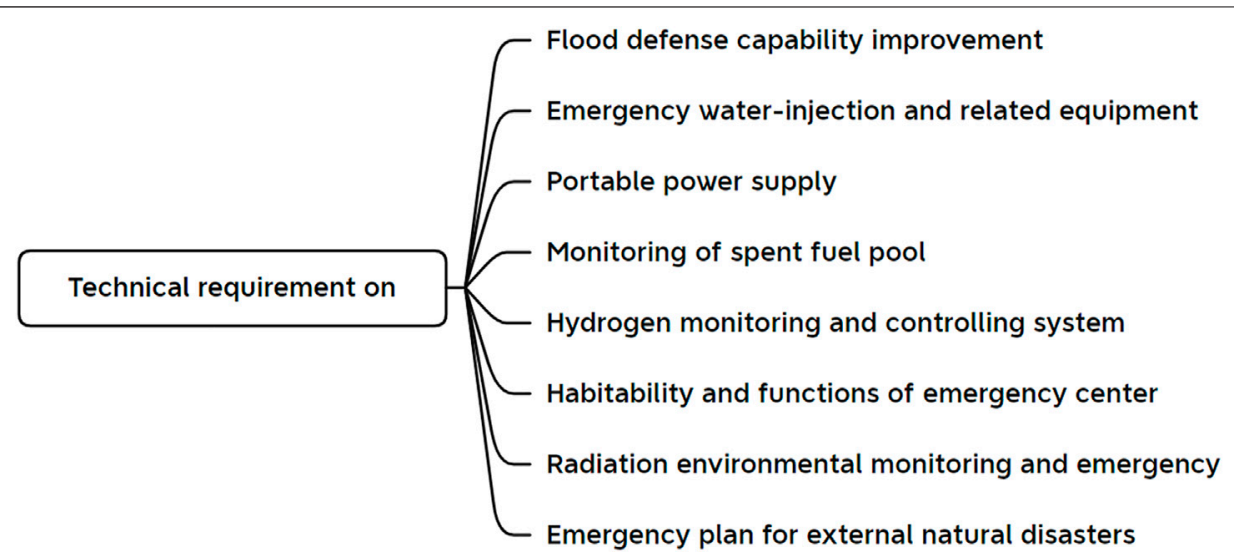

FIGURE 2 | Technical requirements on improvement actions.

TABLE 2 | General conclusions of safety margin evaluation for BDBEE.

\section{Evaluation event}

Anti-seismic margin

Flood safety margin

SBO

\section{Conclusion}

NPPs in operation have a seismic safety margin not less than 1.5 times of the design-basis earthquake NPPs in operation have the safety margin to cope with BDF. For Qinshan NPP on a wet site, it will have the safety margin against BDF after improvement action completion

NPPs in operation have taken measures to keep at least $8 \mathrm{~h}$ of battery power in case of loss of AC power

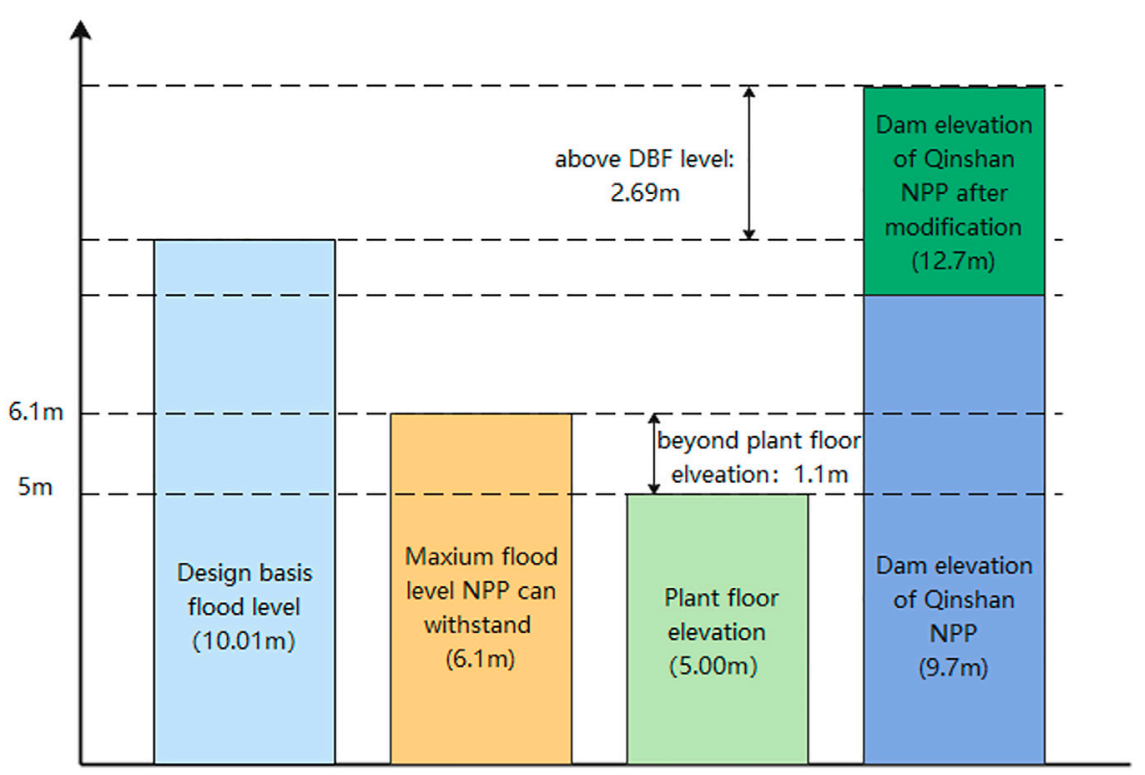

FIGURE 3 | Flood safety margin assessment and improvement of Qinshan NPP.

external events (BDBEEs) and to optimize and implement improvement measures proposed in CSI. The external events selected in the evaluation covered earthquake (initiating event), flood (initiating event), and SBO (with subsequent safety system failures). The general conclusions are shown in Table 2. In Qinshan NPP, plant floor elevation is $5.00 \mathrm{~m}$, the design-basis flood (DBF) level is $10.01 \mathrm{~m}$, and the dam elevation of Qinshan NPP is $9.70 \mathrm{~m}$, which means that flood can occur. When flood occurs, the maximum flood level that an NPP can withstand is $1.1 \mathrm{~m}$ higher than plant floor elevation. After modification, the dam elevation of Qinshan is $12.7 \mathrm{~m}$, and compared with $\mathrm{DBF}$, there is a $2.69-\mathrm{m}$ safety margin for the 
external flood. Now, the modification has been completed (Figure 3).

\section{Nuclear Safety Plan}

China makes medium- and long-term development plans for nuclear safety every 5 years under the framework of the Five-Year Plan for National Economic and Social Development. The NNSA has released the 12th Five-Year Plan for Nuclear Safety and Radioactive Pollution Prevention and Control and Vision for 2020 (NNSA, 2012b) and the 13th Five-Year Plan for Nuclear Safety and Radioactive Pollution Prevention and Control and Vision for 2025, analyzing the situation, clarifying guidelines and principles, and defining goal indicators, key tasks and projects, and supportive measures for nuclear safety. These plans have helped effectively improve our nuclear safety and regulatory capacity.

The 12th Five-Year NSP and another plan developed by the National Energy Administration (NEA), named the Chinese Nuclear Power Safety Plan, set the safety goal for new NPP designs in China for a period in the future; the important ones are as follows:

- During the 12th five-year plan period (before 2015), the new NPP designs should have comprehensive measures to prevent and mitigate severe accidents, the core damage frequency (CDF) should be lower than $10^{-5} / \mathrm{yr}$, and the large release frequency (LRF) should be lower than $10^{-6} / \mathrm{yr}$.

- For NPPs built in and after the 13th five-year plan period (after 2015), efforts should be made to practically eliminate the possibility of large radioactive release in the design.

- Adopting the highest nuclear safety requirements in the world, new NPP designs should comply with the thirdgeneration safety standards.

According to the 13th Five-Year NSP, the lessons learned from the FDNA should be continually studied and the "Code on the Safety of Nuclear Power Plant Design” (HAF102-2004) should be further revised.

\section{Safety Requirements on New NPP Designs and Code on the Safety of the Nuclear Power Plant Design}

The safety requirements on new NPP designs were compiled by the NNSA to implement the high-level safety goal given in the 12th Five-Year NSP and Nuclear Power Safety Plan. The safety requirements on new NPP designs were based on laws, rules, standards in force, and latest IAEA safety standards. The preliminary experience feedback from the FDNA and the results of CSI, as well as the improved actions adopted around the world, were also reflected. The design, construction, and operation experience in China were fully taken into account.

In 2016, No SSR-2/1 (Rev. 1), Safety of Nuclear Power Plant: Design was issued by the IAEA, which incorporated the lessons and experiences learned from the FDNA (IAEA, 2016a). The NNSA decided to take No. SSR-2/1 as a reference, in conjunction with the draft version of safety requirements on new NPP designs, and revise the HAF102-2004 Code on the Safety of Nuclear Power Plant Design. And the new version, HAF102-2016, was published by the NNSA in October 2016 (NNSA, 2016).

\section{Safety Guides and Technical Documents of HAF102-2016}

Many new nuclear safety concepts and requirements were put forward in HAF102-2016 Code on the Safety of Nuclear Power Plant Design. And the IAEA has been already or is developing safety guides and technical documents to give specific methodologies on how to implement these new concepts and requirements, such as IAEA TECDOC-1791 (IAEA, 2016b), SSG2 (IAEA, 2019), and SSG-30 (IAEA, 2014). Also, in China, a safety guide, namely, HAD, of HAF102-2016 should be revised. On the other hand, the number of new NPPs under construction in China is the largest around the world, so it is a necessary work to give the specific criteria for these requirements, which will be a basis for the design and safety review.

Until now, the NNSA has already completed some of the HAD documents, such as HAD102-01 Deterministic Safety Analysis for Nuclear Power Plants, HAD102-07 Design of the Reactor Core for Nuclear Power Plants, and HAD 102-13 Design of Electrical Power Systems for Nuclear Power Plants. Meanwhile, some technical policy documents were also developed by the NNSA to provide the technical position. The Nuclear Safety Review Guideline of NPPs adopting the HPR1000 gives the review methodology on practical elimination of large or early radioactive release, design extension condition analysis and criteria, and portable equipment configuration. Several technical policies, such as the technical policy on cyber security and the technical policy on configuration risk management, put forward technical positions on some specific safety issues. Some safety guides and technical documents are still under development.

\section{STUDY OF NEW SAFETY PHILOSOPHY IN THE POST-FUKUSHIMA ERA}

In conjunction with the safety review practice, the technical position and application of new safety goals, philosophy, and concepts were elaborated and discussed.

\section{New Safety Goal}

Although no loss of life and no significant increase in cancer risk due to radiological releases from the FDNA were found, the radioactive releases resulted in radiological exposure to the workers at the site and the general public residing in the surrounding communities and caused radiological contamination of the environment in those areas, which caused huge social and economic impacts in Japan and around the world. So, the consequence of the FDNA was definitely unacceptable. Some current safety goals, such as the two 0.1 percent related to CDF and LRF, may not be enough to protect the people and public (Bier et al., 2014). In China, the IAEA safety goal, practical elimination of large or early radioactive releases, is adopted in the Nuclear Safety Plan and HAF102-2016 as a new safety goal. 
TABLE 3 | Enhanced defense in depth level structure.

\begin{tabular}{|c|c|c|c|}
\hline $\begin{array}{l}\text { Level } \\
\text { of DID }\end{array}$ & Safety goals & Basic measures & Plant states \\
\hline 1 & Prevention of abnormal operation and failure & $\begin{array}{l}\text { Conservative design and high-quality construction and } \\
\text { operation }\end{array}$ & Normal operation \\
\hline 2 & Control of abnormal operation and detection of failures & $\begin{array}{l}\text { Control, limiting, and protection system and other surveillance } \\
\text { features }\end{array}$ & $\begin{array}{l}\text { Anticipated operational } \\
\text { occurrence }\end{array}$ \\
\hline 3 & Control of accidents within design basis & $\begin{array}{l}\text { Engineered safety features and emergency operating } \\
\text { procedures }\end{array}$ & $\begin{array}{l}\text { DBA, single failure postulated } \\
\text { initial event }\end{array}$ \\
\hline 4 & $\begin{array}{l}\text { Control of severe accident, including prevention of } \\
\text { severe accident (4a) and mitigation of consequence (4b) }\end{array}$ & Additional safety systems and severe accident management & $\begin{array}{l}\text { DEC, including multiple failures } \\
\text { (4a) and severe accident (4b) }\end{array}$ \\
\hline 5 & $\begin{array}{l}\text { Emergency rescue work on extremely condition, } \\
\text { mitigation of off-site radioactive release }\end{array}$ & $\begin{array}{l}\text { Safety margins, supplementary safety measures, DID } \\
\text { measures, extensive damage mitigation, off-site emergency } \\
\text { response }\end{array}$ & $\begin{array}{l}\text { Residual risks, that is, extensive } \\
\text { damage state }\end{array}$ \\
\hline
\end{tabular}

In the Nuclear Safety Review Guidelines of NPPs, adopting the HPR1000, the scope, methodology, and supporting probabilistic judgment value $\left(10^{-7} / \mathrm{yr}\right)$ for "practical elimination" was provided. Practical elimination of large or early radioactive releases is a high-level and overall safety goal, and it is related to defense in depth, DBA, design extension condition (DEC), and corresponding design safety features. Complete design and safety analyses are mandatory to demonstrate this goal, which include deterministic safety analysis as well as probabilistic safety assessment (PSA). When the specific scenarios should be practically eliminated, first, corresponding design features should be incorporated and reliable, and PSA should be used to support the demonstration (low probability less than $10^{-7} / \mathrm{yr}$ ).

\section{Safety Philosophy}

\section{Enhancement of Defense in Depth}

The defense in depth (DID) principle was re-examined, and its importance was confirmed by the FDNA. In China, two enhancement approaches of the DID principle have been studied, emphasizing the effectiveness of DID and the independence between all DID levels.

A proposed enhanced DID-level structure is summarized in Table 3. First, the DID levels were enhanced. The fourth level, which addresses the DEC, was divided into two parts. The fifth level was improved to address the residual risk. For the DBA, engineered safety features were used, and effectiveness should be demonstrated via conservative analysis. For the DEC, additional safety systems were used, and the best estimate and realistic analysis can be used. For the fifth level, supplemental safety measures were used to minimize the consequences of residual risk as far as possible. In the new DID approach, the multi-failure accident and severe accident conditions should be emphasized in the NPP design process, and the design features should be reliable and effective. The prevention and mitigation of accident should be equally addressed.

Second, the independence between all levels should be taken into account. In HAF102-2016, the levels of DID must be as independent as practicable, and safety features for DECs (especially features for mitigating the consequences of accidents involving the melting of fuel) should be independent of safety systems as far as practicable. How to realize this requirement as far as practicable has been discussed widely in the regulatory and design sides. The independence between all DID levels would be beneficial for the enhancement of nuclear safety. Some systems used in severe accident, such as the heat removal system from the reactor core or containment, and the electric power system for the important equipment and instrument, should be independent as far as possible. For example, in-vessel retention (IVR) is adopted in HPR1000 to perform heat removal function in severe accident, which is independent with the emergency core cooling system (ECCS) in DBA. On the other hand, it is impossible to guarantee all systems and equipment to be independent, such as some passive barriers, including the reactor pressure vessel (RPV) and the containment itself. In China, specific requirement on the independence between each DID level is not the same if the design philosophy is different, and should be addressed specifically.

\section{The Application of Risk-Informed Approach}

China always attaches importance to the application of PSA in the nuclear safety regulation. The technical policy on the application of PSA in the nuclear safety was issued by the NNSA in 2010. The PSA can be a useful tool in conjunction with the deterministic method to assess the overall safety level and guide improvement via identifying the weakness. On the other hand, the limited human resources are used to improve the efficiency, depth, and breadth of nuclear safety regulation based on performance-based and risk-informed approaches. The safety and economy of the NPP design are also balanced. A typical example in the design process is the risk-informed safety classification of structure, system, and components (SSCs). In terms of operation, China is also trying to strengthen the risk-informed approach application in technical specifications, maintenance rules, and so on. The risk-informed design and regulation approach is under discussion and is prepared to reflect in a high-level requirement document.

\section{Advocating as High as Reasonably Achievable}

Safety priority philosophy should be carried out since it is the premise and lifeline of nuclear energy development. Economy is also important because it is the basis of nuclear power development. The balance between safety and development has been discussed widely in the nuclear industry. Due to the limitations of human cognition, the severity of consequences, nuclear safety as high as reasonably achievable (AHARA) is 


\section{\begin{tabular}{|c|c|c|c|c|} 
Operational states & \multicolumn{2}{|c|}{ Accident conditions } \\
operation & $\begin{array}{c}\text { Anticipated } \\
\text { operational } \\
\text { occurrences }\end{array}$ & $\begin{array}{c}\text { Design basis } \\
\text { accident }\end{array}$ & \multicolumn{2}{|c|}{$\begin{array}{c}\text { Design extension } \\
\text { conditions }\end{array}$} \\
& & $\begin{array}{l}\text { Without } \\
\text { significant } \\
\text { fuel } \\
\text { degradation }\end{array}$ & $\begin{array}{l}\text { with } \\
\text { core } \\
\text { melting }\end{array}$
\end{tabular}}

FIGURE 4 | Plant states considered in the design

suggested to be considered in the design of NPPs. The AHARA philosophy is with reference to AHARA principles of radiation protection and risk AHARA requirements of the United Kingdom. Actually, this philosophy is always used, though not mentioned in requirement up to now, in practice in China. For example, the IVR strategy was adopted actively by the designer in the Yangjiang NPP Units 3 and 4 before the FDNA occurred.

Safety and development are both considered in AHARA philosophy, which encourage adopting effective and reasonable achievable measures to improve the safety of the NPP design, even if the requirement is already met. AHARA philosophy can improve the nuclear safety continually with the up-to-date technology and research achievements, and update nuclear safety requirements through the summary of nuclear safety improvement practice and experience. Now, the AHARA philosophy is being studied, and relevant guidance is not established.

\section{Safety Requirements \\ Categories of Plant States}

Categories of plant states were optimized in HAF102, and the DEC concept was adopted. A part of beyond design-basis accidents (BDBAs) was considered as DECs, and relevant DEC safety features, as well as their design criteria, was identified, which was intended to enhance the plant's capability to withstand accidents that are more severe than DBAs. The plant states considered in design are shown in Figure 4. There are two categories of the DEC: DEC-A without significant fuel degradation and DEC-B with core melting. However, it must be noted that the DEC is only a part of the BDBA, and so there are conditions other than DECs which cannot be considered in the design of NPPs. These conditions should be practically eliminated, which are called conditions "practically eliminated" or "residual risk." It is not necessary to consider residual risk specifically in the design but can be treated through a safety margin in DID and accident management measures as far as possible. The plant states considering residual risk is shown in Figure $\mathbf{5}$.

Compared to the single failure postulated initial event considered in DBA, the multi-failures are considered in the DEC. The DEC is a postulated plant state, and for the same reasons that design-basis hazards are not considered in DBA, more severe hazards are not considered in DECs as well, although they might result in a DBA or a DEC. The Nuclear Safety Review Guidelines of NPPs adopting the HPR1000 and HAD102-01 provided the DEC identification principle and typical accident list. Best estimate and realistic analysis can be used in the DEC

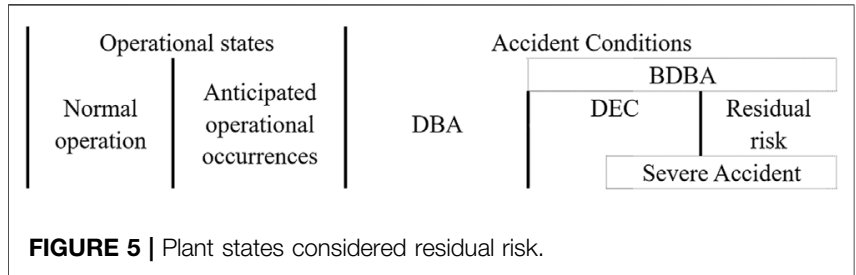

analysis. Technical acceptance criteria of DEC-A and DEC-B should be no fuel melting and containment integrity. And for radiological acceptance criteria, DEC-A should demonstrate that the effective dose received by any individual at the exclusion area boundary is below $10 \mathrm{mSv}$. However, some quantitative criteria are still not clear, such as the probabilistic cutoff value frequency of DEC, and the radiological acceptance criteria of DEC-B, which are related to radiation protection and other factors. In practice, relatively conservative methodology was used, and the results showed a considerable margin compared with domestic standards, which is considered an acceptable practice.

\section{Safety Classification and Availability}

In HAF102-2016, the safety features for the DEC are obviously items important to safety, and the reliability and availability should be guaranteed. However, there are still confusions and discussions. From the viewpoint of the deterministic approach, it is difficult to ensure the availability of safety features for the DEC when the safety system for DBA fails, if there is no high requirement. From the viewpoint of the probabilistic approach, the probability of the DEC is lower than DBA, so the requirement of safety features for the DEC should be comparatively low. In practice, the latter one seems preferred. Safety features for the DEC can be non-safety classification, but equipment availability under severe accident conditions should be demonstrated, and no higher seismic requirement is required.

\section{Commercial Aircraft Impacts}

9/11 events in 2001 brought the commercial aircraft impact issue to the nuclear safety. In HAF102-2016, the relevant requirement was given. The design should take into account the effects of malicious aircraft crash in the event that the NPP might suffer such crashes due to its topographical conditions. An appropriate type of commercial aircraft should be selected to evaluate the effects of the aircraft crash, and the aviation fuel loading should be calculated based on the relative distance between the NPP site and the take-off/ landing airport of that type of aircraft. The angle and speed of the potential aircraft crash can be determined as per the topographical conditions and the layout of the NPP, and crash-proof measures for the plant should be assessed and determined using realistic analyses. The assessment results should demonstrate that the plant design is capable of maintaining reactor core cooling (or containment integrity) and spent fuel cooling (or spent fuel pool integrity).

The technical policy on NPPs withstanding commercial aircraft Impacts is being developed by the NNSA to give guidance on how to meet the requirement in HAF102-2016. For new NPP designs, the commercial aircraft impact should be included 
in the design process. And for operating NPPs, accident mitigation measures should be considered as far as possible. The policy also clarified that some kind of information should be incorporated in the public safety analysis report, while others should be classified and not open to the public.

\section{Portable Equipment Configuration}

The importance of portable equipment was confirmed from the feedback of the FDNA. Specific requirement is being developed in some countries, such as the FLEX strategy of the United States (NEI, 2016). Portable equipment relevant requirement was put forward in HAF102-2016. Each unit of a multiple unit NPP must have its own safety systems and must have its own safety features for DECs. To further enhance safety, means allowing interconnections between units of a multiple unit NPP must be considered in the design. For multiple unit plant sites, the design must properly consider the potential for specific hazards to impact on several or even all units on the site simultaneously. According to GTR (trial version), NPPs may analyze and assess their emergency response capabilities based on the conditions of two reactors being in accident simultaneously. Arrangement of the portable pumps should be considered to meet the need of core cooling and spent fuel pool cooling simultaneously, and at least two sets of equipment should be equipped on one multiple unit plant site. At least two portable power supplies should be equipped, and no less than one of them should have the capability of carrying a low-pressure safety injection pump or an auxiliary feedwater pump, and the necessary monitoring, communication and ventilation loads, etc., should also be included. Other requirements on layout, location, distance, and preparation time are also mentioned.

There are some sites in China involving multiple units, that is, usually 4-6 units are built at one site. In the WANO assessment, relevant questions were put forward by assessment experts. This issue is also discussed widely in China. There are some specific features of Chinese NPPs. First, the site condition of the NPPs is relatively good, and the probability of the beyond designbasis external event is extremely low. Second, the design standard of NPPs in China is relatively new, most of which have the ability to cope with the SBO condition. After the Fukushima nuclear accident, the ability of prevention and mitigation of severe accident was also improved. Besides the portable equipment on site, other portable equipment in nearby NPPs, nuclear region rescue centers, and conventional region rescue centers can also be used. Therefore, it is a problem needed to be studied in China on how to configure portable equipment properly.

\section{CONCLUSION AND PERSPECTIVE}

The lessons and experience learned from the Fukushima nuclear accident can be a long process, and some further enhancement actions probably would be necessary in the future along with the additional research and study on the accident. A series of nuclear safety enhancement actions were taken in China in recent years after the Fukushima nuclear accident based on preliminary lessons and experiences. Higher safety requirements were put forward, and the safety level of NPPs in China has elevated, which obtained positive recognitions in domestic and international organizations (IAEA, 2016c; Lam et al., 2018). The postFukushima nuclear safety enhancement actions in China were summarized. Based on the application and discussion of nuclear safety philosophy and requirements in China, the future development of nuclear safety was discussed preliminarily, and the following suggestions were put forward.

New safety goal and high-level safety requirements were established in China, while some specific requirement and criteria are still being studied and discussed. Relevant safety guides and technical document should be improved, and a complete and logic nuclear safety regulation system should be established.

1) Detail innovation and assessment criteria of practical elimination of large or early radioactive release.

2) Assessment criteria of independence between all defense in depth levels.

3) Balance and combination of deterministic and probabilistic approaches, such as application of the risk-informed approach, AHARA philosophy, and the safety requirement on the design feature for design extension condition.

4) The establishment of probabilistic cutoff value frequency and radiological acceptance criteria of design extension condition with core melting.

5) Assessment criteria of the beyond design-basis external event in the design.

6) Number and configuration of portable equipment on the multiple unit plant site.

In addition, the requirement discussed in this article only refers to the large pressurized water reactor (PWR). Other types of reactors, such as small modular reactor (SMR), hightemperature gas-cooled reactor (HTGR), and molten salt reactor (MSR) are also in design or under construction in China. The safety goal may be the same, but specific requirement and criteria would be different for these new design reactors, some of which may be completely new and innovative around the world, and it is a challenge work for nuclear safety regulation.

\section{AUTHOR CONTRIBUTIONS}

ZY involved in investigation, discussion, and application of some safety requirements and wrote the article. FL involved in formal analysis and discussions. GC put forward some philosophy originally and involved in discussion and application of all safety requirements.

\section{ACKNOWLEDGMENTS}

The authors gratefully acknowledge the support of the National Key R\&D Program of China (Grant No. 2018YFB1900100). 


\section{REFERENCES}

Bier, V., Corradini, M., Youngblood, R., Roh, C., and Liu, S. (2014). “Development of an Updated Societal-Risk Goal for Nuclear Power Safety,” in PSAM 2014Probabilistic Safety Assessment and Management, Honolulu, Hawaii, USA, June 2014

Hayashi, M., and Hughes, L. (2013). The Fukushima Nuclear Accident and its Effect on Global Energy Security. Energy Policy 59, 102-111. doi:10.1016/ j.enpol.2012.11.046

IAEA (2014). Safety Classification of Structures, Systems and Components in Nuclear Power Plants. Specific Safety Guides. Vienna: IAEA Press.

IAEA (2015). The Fukushima Daiichi Accident. Vienna: IAEA Press.

IAEA (2016). Safety of Nuclear Power Plants: Design. IAEA Safety Standards Series No.SSR-2/1. Vienna: IAEA Press.

IAEA (2016). Considerations on the Application of the IAEA Safety Requirements for the Design of Nuclear Power Plants. TECDOC Series. Vienna: IAEA Press.

IAEA (2016). Integrated Regulatory Review Service (IRRS) Follow-Up Mission to China. Vienna: IAEA Press.

IAEA (2019). Deterministic Safety Analysis for Nuclear Power Plants. Specific Safety Guides. Vienna: IAEA Press.

IAEA (2021). Power Reactor Information. Available at: https://pris.iaea.org/PRIS/ home.aspx (Accessed November 18, 2021).

Lam, J., Cheung, L., Han, Y., and Wang, S. (2018). China's Response to Nuclear Safety Post-Fukushima: Genuine or Rhetoric? Cambridge Working Papers in Economics 1866. Faculty of Economics, University of Cambridge.

NEI (2016). Diverse and Flexible Coping Strategies (FLEX) Implementation Guide. Washington, DC: NEI.

NNSA NEA CEA (2012). Report on the Comprehensive Safety Inspection of Civilian Nuclear Facilities in Mainland China. Available at: http://www.mee.gov.cn/gkml/ hbb/bgth/201206/t20120626_232383.html (Accessed November 18, 2021).

NNSA (2012). General Technical Requirements on post-Fukushima Improvement Actions (Trial Version). Available at: https://www.mee.gov.cn/gkml/hbb/haq/ 201206/t20120615_231698.htm (Accessed November 18, 2021).
NNSA (2012). 12th Five-Year Plan for Nuclear Safety and Radioactive Pollution Prevention and Control and Vision for 2020. Available at: http://www.mee.gov. $\mathrm{cn} / \mathrm{gkml} / \mathrm{hbb} / \mathrm{bgth} / 201206 / \mathrm{t20120626 \_ 232383.html} \mathrm{(Accessed} \mathrm{November} \mathrm{18,} \mathrm{2021).}$

NNSA (2016). Safety of Nuclear Power Plants: Design, HAF102. Beijing, China: NNSA.

State Council Information Office of China (2019). Nuclear Safety in China. Beijing: People's Publishing House.

State Council of China (2021). Report on the Work of the Government. Beijing People's Publishing House.

UK ONR (2014). Safety Assessment Principles for Nuclear Facilities. London, United Kingdom: ONR.

US NRC (2011). Recommendation on Enhancing Reactors Safety in the 21st Century. Washington, DC: NRC.

WENRA (2013). Report Safety of New NPP Designs. Paris, France: WENRA.

Zhang, L., and Li, W. H. (2014). Analysis of Nuclear Power Plant Safety Improvement Action after Fukushima Daiichi NPP Accident. At. Energ. Sci. Techn. 48, 486-491. doi:10.7538/yzk.2014.48.03.0486

Conflict of Interest: The authors declare that the research was conducted in the absence of any commercial or financial relationships that could be construed as a potential conflict of interest.

Publisher's Note: All claims expressed in this article are solely those of the authors and do not necessarily represent those of their affiliated organizations, or those of the publisher, the editors, and the reviewers. Any product that may be evaluated in this article, or claim that may be made by its manufacturer, is not guaranteed or endorsed by the publisher.

Copyright (C) 2022 Yang, Li and Chai. This is an open-access article distributed under the terms of the Creative Commons Attribution License (CC BY). The use, distribution or reproduction in other forums is permitted, provided the original author(s) and the copyright owner(s) are credited and that the original publication in this journal is cited, in accordance with accepted academic practice. No use, distribution or reproduction is permitted which does not comply with these terms. 